\title{
NIVEL INTERMEDIO DEL SISTEMA ESCOLAR EN CHILE: NORMATIVA Y VISIÓN DE LOS SOSTENEDORES ACERCA DE LAS FUNCIONES, PREPARACIÓN PARA EL CARGO Y LAS PRÁCTICAS
}

\author{
Dagmar Raczynski ${ }^{1}$, Rosario Rivero ${ }^{2}$ y Teresa Yáñez ${ }^{3}$
}

\begin{abstract}
RESUMEN
La literatura internacional define las características de los profesionales efectivos de niveles intermedios que logran impulsar procesos de mejoramiento continuo en los aprendizajes y la formación de los estudiantes. En Chile, los sostenedores están en tránsito desde un rol de administrador hacia uno de liderazgo en el plano técnico pedagógico. El artículo revisa las leyes y normativas que han moldeado su rol, para luego mostrar los resultados de una encuesta aplicada a sostenedores que informa de las funciones que realizan y de su importancia, el tiempo que le dedican a distintas actividades, la evaluación de su preparación para asumir las nuevas tareas y el apoyo técnico pedagógico que entregan a sus establecimientos. Los resultados indican que continúan asignando más importancia y tiempo a las funciones administrativas y que si bien liderar en lo técnico pedagógico es considerado importante, le dedican menos tiempo y declaran poca preparación para ello. El artículo da cuenta de la urgencia de formar a los sostenedores en lo que hoy se espera de ellos, en particular, en el ámbito público, considerando la nueva figura legal de los Servicios Locales de Educación Pública.
\end{abstract}

Conceptos clave: escuelas públicas, liderazgo intermedio, política educativa, sostenedores.

\section{MIDDLE LEVEL SCHOOL LEADERSHIP IN CHILE: SUPERINTENDENTS' VIEWS OF THEIR FUNCTIONS, PREPARATION AND PRACTICES}

\section{ABSTRACT}

The international research defines the characteristics of effective middle leaders that boost school improvement and student learning. In Chile, middle leaders, called sostenedores, are moving from a position where their role was administrative to one where they have an instructional and pedagogical role as leaders. After presenting an overview of several educational laws and regulations that have outlined the administrator, or superintendent's' role, , this article shows the results of a survey applied to superintendent's that provides information about their functions, how important they are to them, the time that they spend on different activities, the evaluation of their own preparation to deal with the new assignments and the pedagogical and instructional support that they provide their schools. The results reveal that superintendent's still attribute

1 Pontificia Universidad Católica de Chile, Santiago, Chile. Contacto: oraczyns@uc.cl

2 Universidad Diego Portales, Santiago, Chile. Contacto: rosario.rivero@udp.cl

3 Investigadora independiente, Santiago, Chile. Contacto: mteresayanez@gmail.com 
greater importance and dedicate more time to the administrative functions. While they consider leading pedagogical and instructional issues to be important, they spend less time on them and perceive themselves to be less prepared to execute them. The article concludes highlighting the urgency of training superintendent's on the subjects expected, specifically for those who work in public schools considering the recently created figure of Local Educational Services.

Key concepts: educational policy, middle level leadership, public schools.

\section{Introducción}

La atención de este artículo recae en el nivel intermedio del sistema escolar que conecta técnica y administrativamente el nivel central o macro (Ministerio de Educación de Chile, Mineduc y Sistema de Aseguramiento de la Calidad) con el nivel micro constituido por los establecimientos educativos (escuelas y liceos). La literatura internacional identifica este nivel con el "distrito escolar" y señala que este puede jugar un papel importante para impulsar procesos de mejoramiento escolar que tienen expresión en cambios positivos en el aprendizaje y la formación de los estudiantes. Los estudios identifican los atributos y procesos de "distritos escolares" efectivos, entre los que resaltan:

- el liderazgo con propósito y conducción, centrado en la formación y aprendizaje de los estudiantes y orientado a desarrollar una visión y creencias compartidas en los actores involucrados en la educación acerca de la urgencia —el imperativo ético y moral— de "elevar la vara" y cerrar las brechas de aprendizaje entre los establecimientos y los estudiantes;

- el diseño de una estrategia coherente que responde a las necesidades de corto y mediano plazo y a la sostenibilidad del proceso de mejora en el largo plazo; y

- la implementación coordinada y el monitoreo sistemático que retroalimenta el proceso de mejoramiento a nivel de distrito, establecimiento y aula. 
Asociado con lo anterior, los distritos muestran:

- relaciones colaborativas y de confianza interna en el equipo del nivel intermedio y de este con los establecimientos;

- coordinación y coherencia institucional, alineación de propósitos, definición clara de roles y responsabilidades; y

- una administración ordenada y eficiente, con una gestión de recursos que está al servicio de lo pedagógico y no le reste tiempo a esa tarea (Anderson, 2017; Campbell \& Fullan, 2006; Daly \& Finnigan, 2016; Fullan \& Quinn, 2016; Hargreaves \& Ainscow, 2015; Honig, 2012; Leithwood, 2010; The Wallace Foundation, 2006, 2013; Tognery \& Anderson, 2003; Uribe, Berkowitz, Torche, Galdames y Zoro, 2017; Waters \& Marzano, 2006).

En Chile el nivel intermedio se ha asociado con dos figuras en la gestión escolar: por una parte se encuentran los supervisores del Mineduc insertos en el nivel provincial, encargados de "bajar" la política y sus programas a los establecimientos, entregando información, aclarando procedimientos y, a veces, asumiendo el rol de asesores pedagógicos (Raczynski y Muñoz, 2005; Román, 2006); y, por otro lado, están los sostenedores de establecimientos educacionales públicos (municipales) y particulares.

La figura del sostenedor nace en la década de 1980 con el traspaso de los establecimientos públicos a las municipalidades y los estímulos financieros para la creación de establecimientos particulares, tiempo durante el cual su tarea fue administrar los establecimientos traspasados (sostenedor municipal), así como también los nuevos establecimientos creados en el sector particular. En este caso, administrar implicaba velar por el uso debido de los recursos públicos, el reclutamiento y contratación del personal docente y no docente, y la mantención y cuidado de la infraestructura y el equipamiento de los establecimientos. Sin embargo, con el correr de los años, el rol y las funciones del sostenedor se han ido ampliando y complejizando. En la actualidad, se le ha adjudicado un rol de liderazgo activo para impulsar y consolidar procesos de mejoramiento escolar que se expresen en un fortalecimiento continuo en los aprendizajes y formación de los estudiantes, asignándole así un papel en la mejora de la calidad de la educación. 
En Chile los estudios acerca de la gestión que realizan los sostenedores de establecimientos escolares son variados. Abundan los estudios que comparan los resultados de aprendizaje entre los estudiantes matriculados en el sector municipal y particular subvencionado, controlando por el nivel socioeconómico del estudiantado, así como las investigaciones que se detienen en la evolución del número de establecimientos y de la matrícula entre uno y otro sector. Es más reducido el número de estudios que se ha focalizado en el análisis de la gestión de establecimientos que llevan a cabo los sostenedores. Para el sector municipal se pueden mencionar los trabajos de Espínola, Chaparro, Fuenzalida, Silva y Zárate, 2008; Marcel \& Raczynski, 2009; Larrañaga, Peirano y Falck 2009; Salinas \& Raczynski, 2009; Raczynski y Salinas, 2009; Raczynski, 2012; González, González \& Galdames, 2015; en tanto que para el sector municipal y el particular subvencionado se pueden consignar los trabajos de Raczynski y Muñoz, 2005; Román, 2006; Corvalán, Elacqua y Salazar, 2009; Román, et al., 2016; Carrasco, Bonilla \& Rasse, 2019. El conjunto de estos estudios da cuenta de la precariedad con que los sostenedores, tanto municipales como particulares, gestionan la educación, con ausencia de estrategias de mediano plazo, equipos de trabajo poco profesionalizados y que responden más a directrices centrales de política que a las necesidades locales. En uno y otro sector es posible encontrar sostenedores con experiencias interesantes, aunque en general las del sector municipal han carecido de continuidad, debido al cambio de jefaturas en educación cada cuatro años, junto con la rotación de alcaldes. En el sector particular, en tanto, algunas iniciativas de fundaciones o corporaciones asociadas a gremios empresariales tienen un desarrollo sólido y continuo en el tiempo, aproximándose a lo que la literatura señala como "liderazgo efectivo del nivel intermedio".

Este artículo profundiza en el rol actual de los sostenedores de establecimientos escolares en Chile. En primera instancia se presentan las normativas y los cuerpos legales que han plasmado las funciones y atribuciones vigentes del nivel intermedio en Chile. Posteriormente, se ofrece la mirada de los sostenedores acerca de las funciones que realizan y la importancia que les asignan a las mismas, el tiempo que le dedican a distintas actividades y el apoyo técnico 
pedagógico que declaran entregar a sus establecimientos, junto con la autoevaluación de su preparación para asumir las nuevas tareas. La sección final concluye con reflexiones en torno a la magnitud del desafío que enfrentan los sostenedores —en particular los del sector público-, trazando algunas directrices o prioridades de investigación y de política, a fin de consolidar el liderazgo del nivel intermedio e impulsar procesos de mejoramiento escolar, que se expresen en una formación y aprendizajes cada vez más sólidos en los estudiantes.

De esta forma, comprender el rol de los sostenedores en Chile y conocer su propia visión al respecto es crucial, ya que la política vigente implica una transformación profunda en la cultura y en las prácticas de trabajo habituales de la mayoría de los sostenedores de educación en el país. Entonces, si su visión y prácticas no concuerdan con el rol que el sistema espera para ellos, al tiempo que se perciben a sí mismos como poco preparados para asumir sus funciones, será difícil —o casi imposible-, que efectivamente modifiquen sus prácticas, frenando con ello los esfuerzos por mejorar la calidad de la educación escolar en el país.

\section{La legislación y las normativas que han modelado el rol del sostenedor}

Para comprender el rol y funciones que se esperan del sostenedor en la actualidad se requiere revisar varias políticas importantes, aunque ninguna de estas ha sido diseñada especialmente con esta finalidad.

El presente punto describe las iniciativas políticas que han ido configurando los perfiles, estándares, competencias y marcos de acción para el rol del sostenedor, así como las instancias de formación para quienes ocupan cargos en el nivel intermedio. La Tabla 1 lista las principales iniciativas legales en orden cronológico de aprobación. Solo la última de ellas — Ley de Nueva Educación Pública — define explícitamente y en detalle el rol esperado del sostenedor, así como sus atribuciones y requerimientos. 
Tabla 1

Leyes que reconocen y mencionan la figura del sostenedor de educación en responsabilidades más allá de lo administrativo

\begin{tabular}{|c|c|c|c|c|}
\hline Año & $\mathrm{N}^{\circ}$ Ley & Materias & Referencia al sostenedor & $\begin{array}{c}\text { Si aplica a } \\
\text { sostenedor } \\
\text { público o } \\
\text { privado } \\
\text { subvencionado }\end{array}$ \\
\hline 2008 & 20.248 & $\begin{array}{l}\text { Subvención Escolar } \\
\text { Preferencial (SEP). } \\
\text { Subvención adicional } \\
\text { para estudiantes } \\
\text { que califican de } \\
\text { prioritarios. }\end{array}$ & $\begin{array}{l}\text { Cada establecimiento } \\
\text { con su sostenedor define } \\
\text { su plan de mejoramiento } \\
\text { educativo (PME). }\end{array}$ & $\begin{array}{l}\text { Municipales } \\
\text { y particulares } \\
\text { subvencionados. }\end{array}$ \\
\hline 2009 & 20.370 & $\begin{array}{l}\text { Ley Gen eral } \\
\text { de Educación. } \\
\text { Sistema educativo; } \\
\text { proyecto educativo; } \\
\text { comunidad educativa; } \\
\text { consejo escolar; } \\
\text { registro público de } \\
\text { sostenedores; Agencia } \\
\text { de Calidad de la } \\
\text { Educación. }\end{array}$ & $\begin{array}{l}\text { El sostenedor es parte de } \\
\text { la comunidad educativa } \\
\text { y tiene responsabilidades } \\
\text { para con ella más allá de } \\
\text { lo administrativo. }\end{array}$ & $\begin{array}{l}\text { Municipales } \\
\text { y particulares } \\
\text { subvencionados. }\end{array}$ \\
\hline 2011 & 20.501 & $\begin{array}{l}\text { Calidad y equidad de } \\
\text { la educación. Afecta la } \\
\text { educación pública. }\end{array}$ & $\begin{array}{l}\text { Refuerza la lógica } \\
\text { de desem peño y } \\
\text { orientación a resultados } \\
\text { para sostenedores y } \\
\text { directores. Decisión de } \\
\text { seleccionar directores } \\
\text { y jefe de Departamento } \\
\text { de Administración de } \\
\text { Educación Municipal } \\
\text { (DAEM) y corporaciones } \\
\text { m un i c i p a les d e } \\
\text { educación por el Sistema } \\
\text { de Alta Dirección Pública } \\
\text { (SADP). }\end{array}$ & Municipales. \\
\hline 2011 & 20.529 & $\begin{array}{l}\text { Sistema Nacional } \\
\text { de Aseguramiento } \\
\text { de la Calidad de la } \\
\text { Educación (SAC). } \\
\text { Relativo a su } \\
\text { fiscalización, precisa } \\
\text { roles del Mineduc, } \\
\text { Agencia de Calidad, } \\
\text { Superintendencia } \\
\text { de Educación y } \\
\text { Consejo Nacional de } \\
\text { Educación. }\end{array}$ & $\begin{array}{l}\text { Mandata al Mineduc } \\
\text { a definir estándares } \\
\text { indicativos de } \\
\text { desempeño para } \\
\text { sostenedores que } \\
\text { serán evaluados por la } \\
\text { Agencia de Calidad de la } \\
\text { Educación. }\end{array}$ & $\begin{array}{l}\text { Municipales } \\
\text { y particulares } \\
\text { subvencionados. }\end{array}$ \\
\hline
\end{tabular}




\begin{tabular}{|c|c|c|c|}
\hline 2014 & $\begin{array}{l}\text { Documento } \\
\text { Mineduc }\end{array}$ & $\begin{array}{l}\text { Estándares indicativos } \\
\text { de desempeño para } \\
\text { establecimientos } \\
\text { educacionales y sus } \\
\text { sostenedores. }\end{array}$ & $\begin{array}{l}\text { Señala que el sostenedor Municipales } \\
\text { es el responsable de los y particulares } \\
\text { resultados y la viabilidad subvencionados. } \\
\text { del establecimiento. } \\
\text { Define seis estándares } \\
\text { para el sostenedor (ver } \\
\text { Tabla 2). }\end{array}$ \\
\hline 2015 & 20.845 & $\begin{array}{l}\text { Inclusión social. Pone } \\
\text { fin al lucro y al copago } \\
\text { en la educación y } \\
\text { define un sistema } \\
\text { único centralizado de } \\
\text { admisión escolar. }\end{array}$ & $\begin{array}{l}\text { Fin al lucro y Particulares } \\
\text { copago afecta al subvencionados. } \\
\text { sostenedor particular } \\
\text { subvencionado. }\end{array}$ \\
\hline 2016 & 20.903 & Estatuto docente. & $\begin{array}{l}\text { Nueva carrera docente. Municipales } \\
\text { Mentoría a docentes y particulares } \\
\text { nuevos, responsabilidad subvencionados. } \\
\text { del director con apoyo } \\
\text { de sostenedor. Afecta } \\
\text { los estándares de } \\
\text { desempeño para los } \\
\text { establecimientos y sus } \\
\text { sostenedores. }\end{array}$ \\
\hline 2017 & 21.040 & $\begin{array}{l}\text { Ley de Nueva } \\
\text { Educación Pública. }\end{array}$ & $\begin{array}{l}\text { Reestructura la educación Municipales. } \\
\text { administrada por los } \\
\text { municipios. Creación de } \\
\text { la Dirección Nacional } \\
\text { de Educación Pública } \\
\text { (DNEP) y } 70 \text { Servicios } \\
\text { Locales de Educación } \\
\text { Pública (SLEP). }\end{array}$ \\
\hline
\end{tabular}

Fuente: Elaboración propia a partir de cuerpos legales y normativas.

A mediados de la primera década del año 2000 la política escolar puso un énfasis creciente en fomentar el liderazgo directivo en la unidad básica del sistema: los establecimientos escolares. Estas directrices se consolidaron en 2005 con la Ley No 19.979 que llama a los directores a dirigir y liderar el Proyecto Educativo Institucional (PEI) y con la formulación del Marco para la buena dirección (MBD) (Mineduc, 2005) que define lo que se espera del director y su perfil de competencias asociado ${ }^{4}$. En este contexto no se hace una mención

4 El MBD se reformuló y actualizó en 2015, pasando a llamarse Marco de la buena dirección y liderazgo escolar (MBDLE) (Mineduc, 2015). En esta versión se reconoce que el director de escuela o liceo es apoyado por un equipo directivo en su establecimiento y por el sostenedor, y que el proyecto educativo de su establecimiento debe estar alineado con las directrices de política del sostenedor, las que a su vez deben ser coherentes con la política educativa nacional. 
específica del sostenedor, sino que solo se definen tres prácticas del director que requieren de coordinación con el sostenedor. Por su parte, la Ley de Subvención Escolar Preferencial (Ley No 20.248 SEP) de 2008, la cual establece un aporte estatal adicional por estudiante prioritario que asiste al establecimiento, define las reglas de uso de estos recursos y señala que cada establecimiento y su sostenedor, sobre la base de un diagnóstico detallado de su realidad, deberán definir un plan de mejoramiento y poner en marcha las acciones allí especificadas. Con esta iniciativa se pide al sostenedor no solo administrar los recursos, sino que a partir de un diagnóstico de la realidad de su territorio y de la de sus establecimientos este debe definir el uso de los recursos SEP de modo tal que contribuyan a los procesos de mejoramiento escolar (Raczynski, 2012). La Ley General de Educación (Ley No 20.370) de 2009, entre otros aspectos, reafirma que el sostenedor es parte de la comunidad educativa y tiene responsabilidades con ella, más allá de las materias administrativas.

La Ley No 20.501 de Calidad y Equidad de la Educación aprobada el 2011 referida a la educación pública (municipal) refuerza la corresponsabilidad del sostenedor público (municipal en ese momento) en los resultados de aprendizaje que alcanzan sus establecimientos, para lo cual propone profesionalizar el proceso de selección y designación de sostenedores y directores de escuelas y liceos municipales, quienes deberán someterse al Sistema de Alta Dirección Pública (SADP). Como guía orientadora de este proceso se definieron allí las competencias requeridas por parte de los jefes de educación municipal (así como de los directores de establecimientos). Para los sostenedores se definieron seis ejes de competencias que son: pasión por la educación, visión estratégica, liderazgo, conocimientos técnicos en el ámbito educacional, planificación y administración de recursos y relación con el entorno y redes de colaboración, explicando el contenido de cada eje.

También en 2011 se creó el Sistema Nacional de Aseguramiento de la Calidad de la Educación Parvularia, Básica y Media y su Fiscalización (Ley $N^{0}$ 20.529). Esta ley redefine y crea nuevas instituciones - la Agencia de Calidad (ACE), la Superintendencia de Educación (SIE) y el Consejo Nacional de 
Educación (CNED) — las que se suman al quehacer del Mineduc. Simultáneamente, dicho sistema llama a definir los estándares de desempeño para los establecimientos educacionales y sostenedores, los cuales se publican en 2014 (Mineduc, 2014). Ahí se indica que el sostenedor, así como el director del establecimiento, son líderes en su campo y para el sostenedor establece seis estándares y define cuatro niveles de desarrollo — débil, incipiente, satisfactorio y avanzadopara cada uno, señalando algunas prácticas asociadas a cada nivel. La Tabla 2 lista los estándares e identifica las prácticas que se esperan en el nivel satisfactorio de desempeño.

Tabla 2

Liderazgo del sostenedor: estándares y prácticas asociadas a un nivel de desempeño satisfactorio

Estándares del sostenedor Prácticas del sostenedor asociadas a un desempeño satisfactorio

1. Se responsabiliza del logro Asume la responsabilidad por los resultados del de los estándares de aprendizaje establecimiento.

y de los otros indicadores Da cuenta anual a la comunidad educativa respecto del de calidad, así como del cumplimiento del proyecto educativo institucional, cumplimiento del PEI y de la la normativa vigente y el logro de los estándares de normativa vigente. aprendizaje y de los otros indicadores de calidad. Supervisa y visita, al menos una vez al mes, el establecimiento y maneja la información acerca de este (resultados en estudiantes, indicadores de eficiencia, estado financiero, cumplimiento del PME, etc.).

2. Se responsabiliza por la Define por escrito y de acuerdo con la normativa vigente elaboración del PEI, del PME y los encargados de elaborar, actualizar y revisar el PEI; lo del presupuesto anual. aprueba y hace seguimiento de los avances y problemas. Define por escrito el procedimiento y los encargados de elaborar el presupuesto anual del establecimiento y lo aprueba.

Asegura que se respeten y se cumplan los procedimientos y responsabilidades definidas.

3. Define las funciones de apoyo De acuerdo con el director, define por escrito las funciones que asumirá centralizadamente que asumirá centralizadamente en los ámbitos de gestión y los recursos financieros que de personas, perfeccionamiento, gestión pedagógica, delegará al establecimiento, y apoyo a estudiantes y adquisición de material educativo. cumple con sus compromisos. Se encarga de la gestión financiera y de la mantención de la infraestructura.

Cumple a tiempo con el apoyo comprometido.

4. Comunica altas expectativas Motiva al director a asumir desafíos, analiza con el al director, establece sus atribuciones, define las metas que este debe cumplir y evalúa su desempeño. director los aspectos por mejorar y fijan en conjunto metas desafiantes y alcanzables, las monitorea y retroalimenta (al menos dos veces al año).

Define por escrito los roles y atribuciones del director en los distintos ámbitos de su gestión. 
5. Introduce los cambios Como ejemplo de cambios estructurales se mencionan: estructurales necesarios para modificaciones en el equipo directivo y administrativo, en asegurar la viabilidad y el el tipo de educación ofrecida, política de cobro, tamaño del buen funcionamiento del establecimiento y cursos y fusiones entre establecimientos. establecimiento. Consulta la opinión del Consejo Escolar y del Centro de Padres respecto de los cambios. Explica los cambios a la comunidad educativa.

6. Genera canales fluidos de Se reúne con el director, al menos una vez al mes; atiende comunicación con el director sus llamadas, contesta correos, lo mantiene informado y con la comunidad educativa. acerca de temas pertinentes.

Define, en común acuerdo con el director, el plan de comunicación con la comunidad educativa y respeta lo estipulado.

Está disponible para atender oportunamente las situaciones de crisis y atender denuncias.

Fuente: Mineduc (2014).

En el 2015 se aprobó la Ley No 20.845 de inclusión escolar que puso fin al lucro en la educación y al copago y definió un sistema único centralizado de admisión escolar. Esta ley repercutió en el sostenedor particular, ya que se le impuso la responsabilidad de transformarse en una figura legal sin fines de lucro y la necesidad de abandonar el copago si se adscribía a la gratuidad, recibiendo en cambio mayores recursos públicos y sometiéndose a mayores fiscalizaciones por parte de la Superintendencia de Educación. Por último, tanto los sostenedores de colegios públicos como los de establecimientos particulares subvencionados quedaron obligados a sumarse al nuevo sistema de admisión escolar.

La Ley No 20.903 de 2016, por su parte, actualizó e innovó en el estatuto docente, definiendo el sistema de desarrollo profesional docente y modificando las normas asociadas. Entre otros, dicha legislación precisó una carrera docente con una clasificación en cinco niveles y estableció un sistema de mentoría para los docentes nuevos. Por último según esta ley, la responsabilidad de respetar las directrices del estatuto recae en el director de los establecimientos, señalando que el sostenedor podrá colaborar en la formación para el desarrollo profesional docente, en tanto que algunas leyes posteriores introducirían modificaciones adicionales.

A fines de 2017, después de tres años de discusión parlamentaria, se aprobó la Ley N²1.040 de la Nueva Educación 
Pública, la cual reestructura la educación administrada por las municipalidades, creando una dirección específica, la Dirección Nacional de Educación Pública (DNEP), dependiente del Mineduc y dictamina la instalación paulatina de 70 SLEP. Estos servicios locales están llamados a asumir el liderazgo educativo en el nivel intermedio del sistema, siendo su principal función la de acompañar y apoyar en lo pedagógico a los establecimientos bajo su dependencia para:

- asegurar oportunidades de aprendizaje integral para todos los estudiantes;

- lograr una mejora continua de la calidad en todos sus establecimientos;

- tener acceso y trayectoria fluidas para los estudiantes entre niveles y modalidades de enseñanza del sistema;

- lograr la reducción de las desigualdades de origen o condición de los estudiantes;

- favorecer la colaboración y el trabajo en red entre establecimientos y con actores locales;

- contar con una oferta de proyectos educativos inclusivos y laicos;

- desarrollar actividades de formación ciudadana, diversas y pertinentes a la identidad, necesidades e intereses locales.

Estos elementos constituyen los principios orientadores para la nueva educación pública.

Esta ley define las funciones y atribuciones de la DNEP y los SLEP, así como la relación entre ambos y la de cada SLEP con los establecimientos a su cargo. Con ello, se determinó que a los SLEP les corresponde:

- administrar los recursos humanos, financieros y materiales del servicio y de los establecimientos educacionales de su dependencia;

- diseñar y prestar el apoyo técnico pedagógico a estos últimos;

- implementar iniciativas de desarrollo profesional para los funcionarios y trabajadores del servicio, así como para los directivos, docentes y asistentes de la educación en los establecimientos; 
- diseñar e implementar sistemas administrativos de seguimiento, monitoreo, rendición de cuentas, evaluación de procesos y evaluación de resultados de los establecimientos y determinar su apertura, fusión o cierre;

- fomentar el trabajo colaborativo en red de sus establecimientos;

- velar porque sus establecimientos cuenten con un equipo directivo y docente calificado;

- proveer una oferta curricular acorde al currículo nacional y pertinente al contexto local;

- implementar un sistema de monitoreo y seguimiento del progreso de los aprendizajes;

- velar por el acceso de sus estudiantes a recursos para el aprendizaje, tecnología y bibliotecas;

- fomentar la participación de la comunidad educativa;

- velar por la existencia y mantención de una adecuada infraestructura y equipamiento; y

- promover la calidad y pertinencia de las especialidades técnico profesionales.

Complementariamente, la ley define algunos instrumentos de gestión educacional, por ejemplo, que al momento de su nombramiento, el director del SLEP suscribirá un convenio de gestión educacional (con una duración de seis años) y definirá su plan estratégico local, que contendrá los objetivos, metas, estrategias y acciones para su cumplimiento. Junto con ello cada año este debe definir un plan anual que contempla el avance en el cumplimiento de los objetivos y metas definidos, y una planificación para el año de las acciones de apoyo técnico pedagógico, entre otros, para los establecimientos de su dependencia. Con ello se aprecia que esta ley es, sin duda, la primera que identifica y delinea explícitamente el rol, funciones y responsabilidades que se espera asuma el nivel intermedio, definiendo incluso algunos instrumentos de su gestión ${ }^{5}$,

5 La ley define varios aspectos adicionales que incumben a los SLEP, entre ellos, los de financiamiento e instancias de participación de: los directores de establecimientos (Consejo de Directores); y de participación local (el Comité Directivo Local y el Consejo Local de Educación Pública). Asimismo, define un proceso gradual de implementación de los SLEP que se extiende hasta el año 2025 y un conjunto de disposiciones transitorias. En junio de 2019 se hizo público un informe que sistematiza y evalúa el proceso de implementación de los cuatro primeros SLEP (Uribe et al., 2019). 
en tanto que las iniciativas legales previas solo rozaban estos aspectos al agregar nuevas obligaciones, pero sin una mirada comprehensiva de su quehacer.

Simultáneamente a los cambios legislativos el Mineduc, previa licitación, a partir de 2016 apoyó por cuatro años la formación de dos centros de liderazgo escolar asociados con universidades regionales: Líderes Educativos a cargo de la Universidad Católica de Valparaíso y el Centro de Liderazgo Educativo, CEDLE, a cargo de la Universidad Diego Portales. Ambos centros contemplan una línea de trabajo en la que diseñan e implementan instancias de formación (diplomados) para directivos y profesionales insertos en el equipo del sostenedor, o bien, que aspiran a insertarse en un equipo de este tipo, así como también desarrollan investigaciones aplicadas que recogen y evalúan prácticas en uso, entregan instrumentos de apoyo al trabajo de directivos y profesionales en el nivel intermedio y llevan adelante actividades de apoyo a los profesionales que se desempeñan en los primeros SLEP. El foco de esta línea de trabajo de estos centros es, por tanto, fortalecer las capacidades de liderazgo directivo y de los equipos de trabajo del nivel intermedio, en particular en el área pedagógica, de convivencia escolar y redes de aprendizaje entre establecimientos, directivos y docentes.

Dentro de los productos elaborados durante este proceso resalta la propuesta de Marco para la gestión y el liderazgo educativo local (Uribe et al., 2017), documento que a la fecha es el más actualizado para orientar el desafío de gestión que enfrentan actualmente los directores de los SLEP en formación y para los sostenedores municipales. Los propósitos de este documento son:

sistematizar y explicitar una expectativa compartida sobre la gestión y el liderazgo educativo del nivel intermedio; distinguir un conjunto de ámbitos de acción que deberá abordar el equipo directivo del nivel local de educación para apoyar la generación de condiciones y ambientes de aprendizaje de calidad para los estudiantes de las unidades educativas a su cargo; promover un lenguaje común, que favorezca la comprensión del rol de liderazgo educativo del nivel intermedio para lograr la coherencia 
del sistema; orientar la autorreflexión, la autoevaluación y el desarrollo profesional de los equipos directivos en ejercicio; guiar la formación inicial y en servicio de los directivos del nivel local de educación; y orientar los procesos de reclutamiento, inducción, selección y evaluación de los equipos directivos del nivel local (Uribe et al., 2017, p. 50).

Complementariamente, junto con este documento se han elaborado otros que entregan directrices y herramientas al sostenedor para concretizar las funciones que se le han encargado. Entre ellos se pueden mencionar los trabajos de Ahumada, Castro y Maureira, 2018; Alarcón, 2016; Aziz, Hevia y Rivero, 2018; Berkowitz, Warner \&Zoro, 2018; Horn, Rojas, Navarro, Valencia y Palma, 2017; Muñoz, Valdebenito \& Amenábar, 2018; Rivero, Zoro \& Aziz, 2018; Román et al., 2016.

El Marco para la gestión y el liderazgo directivo local diferencia entre las dimensiones de prácticas y principios, conocimientos y habilidades, siguiendo la lógica del MBDLE. Los principios aluden a los valores y compromisos que se espera asuman todos los integrantes del equipo a nivel intermedio, refieren a lo ético, el compromiso con la tarea, la justicia social, la confianza interpersonal y organizacional, la integridad y probidad. Por su parte, las dimensiones de práctica para la gestión y el liderazgo educativo local son siete:

- Construcción de una visión y estrategia compartida del proyecto educativo territorial.

- Desarrollo de una cultura de inclusión, participación y respeto a la diversidad.

- Liderazgo y gestión de las políticas y procesos educativos a nivel local.

- Desarrollo profesional y distribución con equidad de las capacidades pedagógicas y de liderazgo.

- Gestión de sistemas de información y monitoreo para la mejora educativa.

- Gestión de recursos y condiciones organizacionales para el desarrollo de los PEI. 
- Generación de una cultura de trabajo colaborativo, de calidad y transparente.

Para cada una de ellas, el Marco para la gestión y el liderazgo directivo local define cuál es el desafío y describe lo que debiera hacerse y cómo, agregando evidencias prácticas referidas a acciones por realizar 6 .

La revisión de la legislación y algunas normativas que han incidido y redefinido las funciones de los sostenedores, en particular de los sostenedores públicos, revela un acercamiento a las líneas y directrices de trabajo que se desprenden de la literatura internacional acerca de este nivel, aunque hay algunas diferencias importantes: el SLEP no tiene ninguna tuición respecto de la educación privada subvencionada en su territorio; las instancias de participación de los actores locales son más débiles y sus atribuciones son, principalmente, consultivas y no resolutivas; y, por último, la retroalimentación de lo local a la política nacional no es un elemento que se encuentre explícito en las leyes y normativas. Pese a estas diferencias, lo que la legislación y normativa hoy vigentes esperan del nivel intermedio apunta en una dirección similar a lo que señala la literatura especializada en el tema, esto es:

- Poner lo administrativo y financiero al servicio de lo técnico pedagógico y al mejoramiento en la formación y aprendizaje de los estudiantes.

- Trabajar participativamente o en colaboración con los establecimientos, consolidando las capacidades de gestión y de liderazgo en estos y en sus aulas.

- Tomar decisiones de corto plazo (anuales) en el marco de una estrategia de mediano y largo plazo para el territorio y los establecimientos a su cargo.

- Fomentar y consolidar redes colaborativas y de aprendizaje recíproco entre establecimientos, sus directivos y docentes.

6 La Tabla 3 desplegada más adelante recoge parte de su contenido, diferenciando entre habilidades, conocimientos y prácticas. 
- Adecuar la política nacional de educación a las particulares características sociales, culturales y geográficas del territorio.

2. Visión de los sostenedores de sus funciones: importancia, preparación y prácticas con énfasis en lo técnico pedagógico

Esta sección se detiene en cómo los sostenedores definen su rol y lo concretizan. La información proviene de una encuesta presencial, aplicada entre agosto y octubre de 2018, a una muestra aleatoria de 250 sostenedores de establecimientos de educación básica y media de zonas urbanas del país. El universo del estudio correspondió a los 3.846 sostenedores de establecimientos, donde el 94\% provenía de establecimientos particulares y el $6 \%$ de colegios públicos (municipales y a cargo de SLEP). La muestra intencionó una sobrerrepresentación de sostenedores públicos, dado su número reducido frente a los privados. Cabe mencionar que los sostenedores públicos tienen a su cargo el 44\% de los establecimientos escolares del país (Mineduc, 2018). De esta forma, el 14\% de la muestra correspondió a sostenedores públicos y el $86 \%$ a privados. En relación con otras características disponibles de los establecimientos y sus sostenedores, como el nivel de enseñanza y la zona geográfica, la muestra y el universo fueron similares. El error muestral asociado a esta muestra fue de un $5 \%$, considerando un grado de confianza de $95 \%$.

Para los propósitos de este trabajo se extrajo de la encuesta la información referida a la percepción de los sostenedores respecto de sus funciones, el tiempo dedicado a estas, su preparación y la frecuencia con la que realizan las tareas referidas al ámbito técnico pedagógico, con el propósito de explorar la correspondencia entre el rol que la legislación y normativas vigentes esperan que sean asumidos por ellos y cómo visualizan y concretizan su rol' ${ }^{7}$ El análisis se realizó para el conjunto de la muestra, señalando cuando se observaron diferencias estadísticamente significativas en las respuestas de los sostenedores públicos y privados.

7 Para más detalle de la encuesta ver Rivero, Yáñez, Morandé, Raczynski y Tham, 2018. 
398 NIVEL INTERMEDIO DEL SISTEMA ESCOLAR EN CHILE: NORMATIVA Y VISIÓN DE LOS SOSTENEDORES ACERCA DE LAS FUNCIONES, PREPARACIÓN PARA EL CARGO Y LAS PRÁCTICAS - D. Raczynski, R. Rivero y T. Yáñez

\subsection{Importancia de las tareas administrativas y no administrativas en el quehacer de los sostenedores}

Se solicitó a los sostenedores, en una escala de 1 a 5, que indicaran la importancia que otorgaban a un conjunto de 12 tareas, las que se agruparon en dos categorías, administrativa y no administrativa, y donde esta última incluyó tareas de liderazgo y desarrollo organizacional y técnico pedagógicas. Adicionalmente, entre las 12 tareas se les preguntó por las cuatro a las que dedicaban más tiempo. Los resultados se muestran en la Figura 1. Se aprecia que las tareas asociadas a la función administrativa son las más importantes y también a las cuales destinan más tiempo. Dentro de ellas, destaca por su alto tiempo asignado la gestión de los recursos financieros y humanos de los establecimientos. A las tareas asociadas a la función no administrativa se les asigna alta importancia, en particular, la de promover y fortalecer el liderazgo directivo en los establecimientos. Las restantes tareas no administrativas, sin excepción, se les adjudica menos importancia y se les asigna menos tiempo que a las administrativas. Las tareas no administrativas más priorizadas son la evaluación y monitoreo de resultados educativos de los estudiantes, atraer/mantener la matrícula y asistencia de los estudiantes y promover/fortalecer el liderazgo directivo, con porcentajes de entre $30 \%$ y $40 \%$ de dedicación de tiempo.

En resumen, los sostenedores consideran que las tareas asociadas a las funciones administrativas y no administrativas son importantes, pero la dedicación de tiempo real se concentra, en su mayoría, en las tareas relacionadas con lo administrativo, en desmedro del tiempo para aquellas de liderazgo, desarrollo organizacional y asuntos técnico pedagógicos.

Al desagregar la información anterior según si el sostenedor es público o privado, solo se aprecian diferencias en dos tareas, ambas del ámbito no administrativo. Estas son promover y fortalecer el liderazgo directivo y entregar apoyo técnico pedagógico a los establecimientos. El 51,4\% de los sostenedores públicos señala promover y fortalecer el liderazgo directivo entre las cuatro tareas a las que dedica más tiempo, frente a un $26,5 \%$ de los privados. En 
cuanto al apoyo técnico pedagógico de los establecimientos, los porcentajes correspondientes al sector público y al privado son 42,9 y $25,6 \%$, respectivamente. En síntesis, en cuanto a la declaración de dedicación de tiempo, los sostenedores públicos dedicarían más tiempo que los privados a temas mandatados en la legislación reciente.

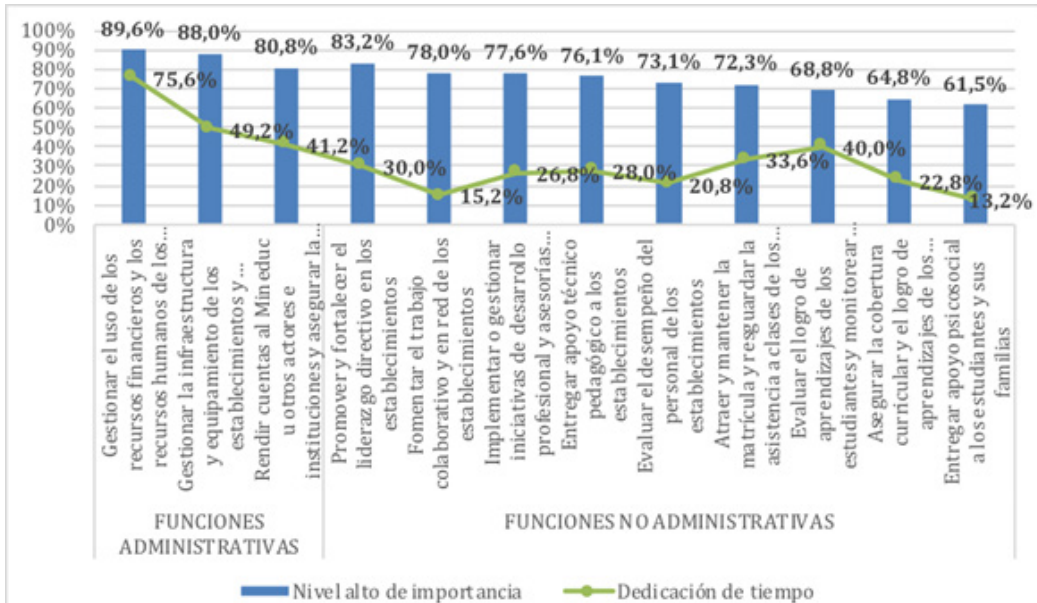

Figura 1. Percepción de la importancia de las funciones y dedicación de tiempo. Fuente: Elaboración propia.

2.2. Preparación que reportan los sostenedores para asumir funciones de liderazgo, desarrollo organizacional y técnico pedagógicas respecto de sus establecimientos

Siguiendo una distinción presente en el marco de actuación para el nivel intermedio elaborado por Líderes Educativos (Uribe et al., 2017) se consultó a los sostenedores acerca de la preparación que dicen tener en habilidades, conocimientos y prácticas para desplegar algunas tareas asociadas al liderazgo, desarrollo organizacional y apoyo técnico pedagógico, presentes en las definiciones vigentes respecto de su rol en este ámbito.

La Tabla 3 sintetiza las habilidades, conocimientos y prácticas consultadas. Respecto de cada uno de los elementos, el sostenedor se autoubicó en una escala de cinco niveles que abarcan desde nada de preparado (1) hasta altamente preparado (5). 
Tabla 3

Prácticas, habilidades y conocimientos consultados a los sostenedores

\begin{tabular}{|c|c|}
\hline Preparación & Prácticas consultadas \\
\hline \multirow{7}{*}{ Prácticas } & $\begin{array}{l}\text { Construir una visión y estrategia compartida del proyecto educativo } \\
\text { de sus establecimientos. }\end{array}$ \\
\hline & $\begin{array}{l}\text { Desarrollar una cultura de inclusión, participación y respeto a la } \\
\text { diversidad en establecimientos. }\end{array}$ \\
\hline & $\begin{array}{l}\text { Liderar y gestionar las políticas y procesos educativos de los } \\
\text { establecimientos a su cargo. }\end{array}$ \\
\hline & Gestionar el desarrollo profesional de los equipos escolares. \\
\hline & $\begin{array}{l}\text { Gestionar sistemas de información y monitoreo para la mejora } \\
\text { educativa. }\end{array}$ \\
\hline & $\begin{array}{l}\text { Gestionar los recursos y condiciones organizacionales para el } \\
\text { desarrollo de la planificación estratégica de los establecimientos o } \\
\text { del PEI. }\end{array}$ \\
\hline & $\begin{array}{l}\text { Generar una cultura de trabajo colaborativo, de calidad y } \\
\text { transparente. }\end{array}$ \\
\hline \multirow{4}{*}{ Habilidades } & $\begin{array}{l}\text { Desarrollar una visión compartida que interprete y analice } \\
\text { críticamente la información para la gestión. }\end{array}$ \\
\hline & $\begin{array}{l}\text { Liderar un trabajo colaborativo en equipo y lograr aprendizajes } \\
\text { colectivos. }\end{array}$ \\
\hline & $\begin{array}{l}\text { Relacionarse con la comunidad y el entorno, generar redes y } \\
\text { comunicarse efectivamente. }\end{array}$ \\
\hline & $\begin{array}{l}\text { Negociar y responder a las contingencias, y manejar situaciones } \\
\text { emergentes. }\end{array}$ \\
\hline \multirow{3}{*}{ Conocimientos } & $\begin{array}{l}\text { Conocimientos de política educativa (tendencia en educación, } \\
\text { inclusión y equidad, política nacional y formación ciudadana, entre } \\
\text { otras). }\end{array}$ \\
\hline & $\begin{array}{l}\text { Conocimientos de enseñanza efectiva y desarrollo docente (gestión } \\
\text { del currículo, procesos de aprendizaje, evaluación y desarrollo } \\
\text { profesional). }\end{array}$ \\
\hline & $\begin{array}{l}\text { Conocimientos de planificación, liderazgo y gestión (liderazgo } \\
\text { escolar, mejoramiento y cambio, gestión de redes y de proyectos). }\end{array}$ \\
\hline
\end{tabular}

Fuente: Uribe et al. (2017).

Con las respuestas obtenidas se construyó un índice de preparación en habilidades, conocimientos y prácticas, diferenciando tres niveles: alto, medio, bajo ${ }^{8}$ (Figura 2). Como se aprecia, menos de la mitad de los sostenedores declara tener un nivel alto de

8 La construcción de índices se realizó clasificando los puntajes obtenidos por los sostenedores en los niveles alto, medio y bajo, a partir de criterios de distribución de sus puntajes, donde para ser clasificado en alto, tenía que calificar en el nivel de mayor preparación en, al menos, un $70 \%$ de los ítems de ese índice, en tanto que para ser bajo, tenía que calificar en, al menos, un 30\% en el nivel de baja preparación. 
preparación en prácticas, habilidades y conocimientos y entre un $18 \%$ y un $26 \%$ se encuentra en un nivel bajo. El nivel bajo es mayor en conocimientos que en habilidades y prácticas. Los sostenedores públicos y privados no se diferencian en cuanto al nivel de preparación que reportan tener en conocimientos, habilidades y prácticas.

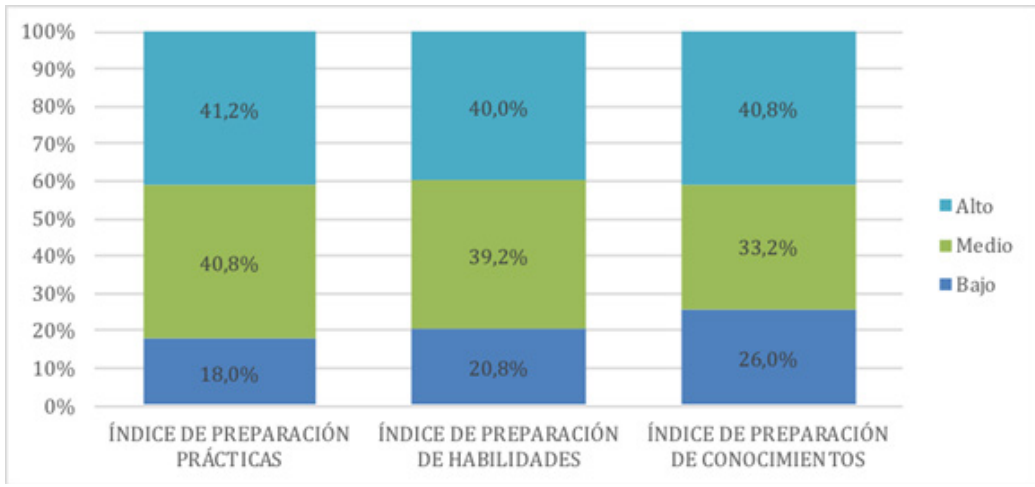

Figura 2. Índice de preparación en prácticas, habilidades y conocimientos.

Fuente: Elaboración propia.

Ahondando en los aspectos específicos (ítems), las Figuras 3, 4 y 5 revelan lo siguiente:

a) Prácticas. Los sostenedores se perciben levemente más preparados para generar una cultura de trabajo colaborativo, apoyar la planificación estratégica de establecimientos en pos de cumplir con su PEI, liderar y gestionar los procesos educativos de los establecimientos, desarrollar una cultura de inclusión, participación y respeto a la diversidad, y construir de una visión y estrategia compartidas del proyecto educativo. Por el contrario, los sostenedores se perciben menos preparados en lo referido al desarrollo profesional de equipos escolares y para gestionar sistemas de información y monitoreo para la mejora educativa. 


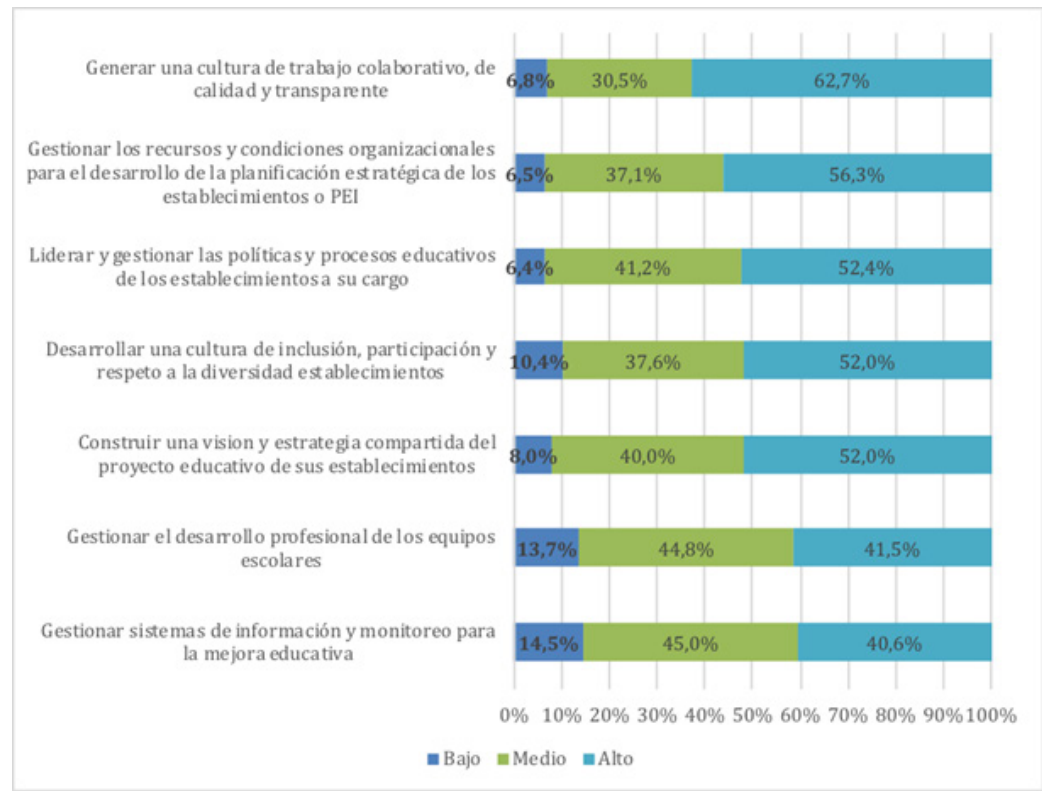

Figura 3. Percepción de los sostenedores acerca de su preparación para la realización de prácticas.

Fuente: Elaboración propia.

b) Habilidades. Los sostenedores declaran un nivel de preparación levemente mayor en habilidades para negociar y responder a las contingencias, liderar un trabajo colaborativo en equipo y lograr aprendizajes colectivos, y relacionarse con la comunidad y el entorno, en desmedro de las habilidades para desarrollar una visión compartida.

c) Conocimientos. El nivel de preparación en los aspectos considerados es relativamente similar y más bajo que en habilidades y prácticas. Más la mitad se encuentra en nivel medio o bajo.

En cuanto a la preparación en conocimientos, habilidades y prácticas, no se observan diferencias estadísticamente significativas entre sostenedores públicos y privados — salvo una excepción—, vale decir, las debilidades en la formación tienden a ser transversales a ambos sectores. Solo en relación con el ítem "conocimiento de enseñanza efectiva y desarrollo docente" los sostenedores privados 
reportan estar más preparados que los públicos (43\% de los privados se autoubican en el nivel alto, en comparación con un 31\% de los públicos).

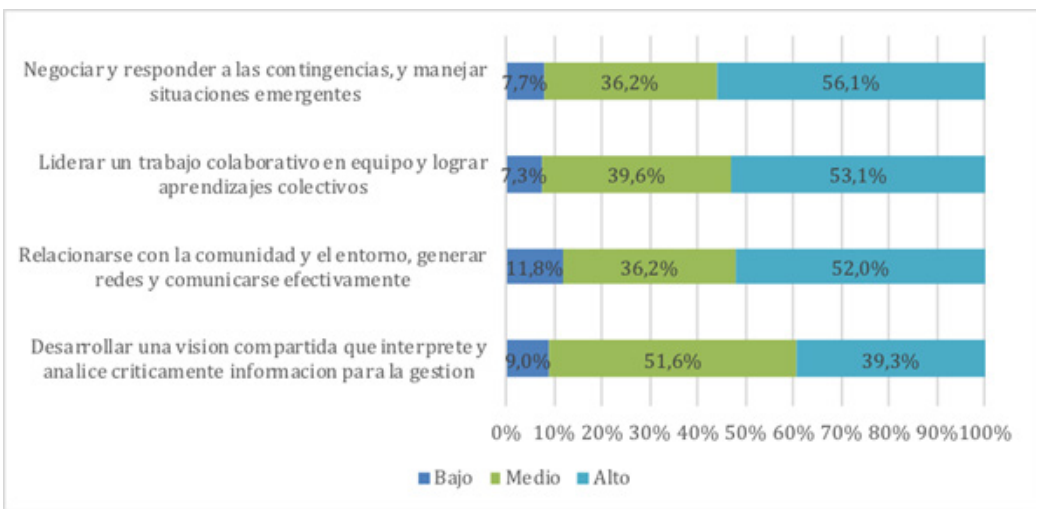

Figura 4. Percepción de los sostenedores acerca de su preparación de habilidades. Fuente: Elaboración propia.

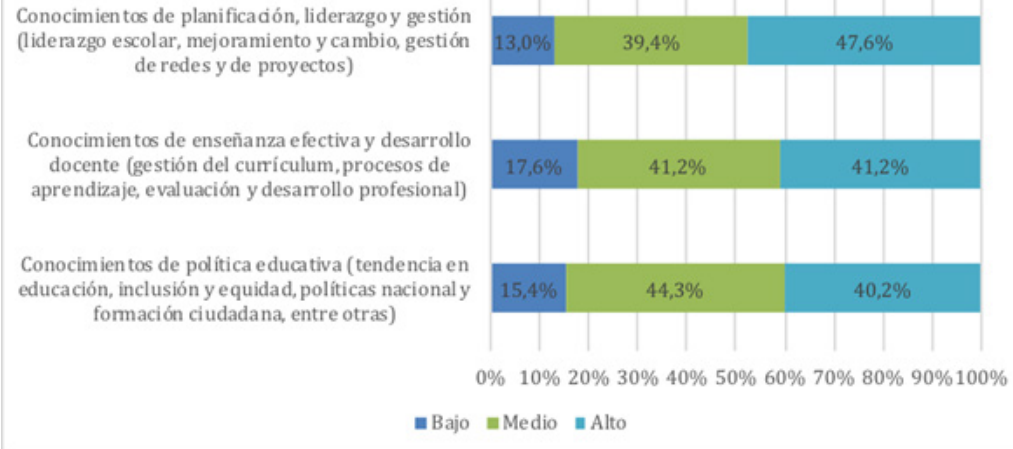

Figura 5. Percepción de los sostenedores acerca de su preparación de conocimientos. Fuente: Elaboración propia.

\subsection{Tiempo destinado a las funciones no administrativas y visión que el sostenedor reporta en cuanto a su preparación}

La pregunta que guio esta sección fue si el tiempo destinado a las funciones no administrativas dependía o no de la preparación para realizarlas. Para ello, se construyó un índice respecto del tiempo 
dedicado a las funciones no administrativas ${ }^{9}$, cuyos resultados se muestran en la Tabla 4. En la última columna se aprecia que mientras más alta es la preparación reportada en conocimientos, habilidades y prácticas, más alto es el tiempo promedio destinado a las funciones no administrativas referidas a liderazgo y desarrollo profesional y materias técnico pedagógicas.

Tabla 4

Índices de funciones no administrativas, según la preparación de prácticas, habilidades y conocimientos

\begin{tabular}{|c|c|c|c|c|}
\hline \multicolumn{2}{|c|}{ Índices de preparación } & \multicolumn{3}{|c|}{ Índice tiempo destinado a funciones no administrativa } \\
\hline & & Bajo & Medio & Alto \\
\hline \multirow{3}{*}{ Prácticas } & Bajo & $22,2 \% *$ & $37,8 \% *$ & $40,0 \% *$ \\
\hline & Medio & $9,8 \% *$ & $21,6 \% *$ & $68,6 \% *$ \\
\hline & Alto & $7,8 \% *$ & $11,7 \% *$ & $80,6 \% *$ \\
\hline \multirow{3}{*}{ Habilidades } & Bajo & $21,2 \% *$ & $21,2 \% *$ & $57,7 \% *$ \\
\hline & Medio & $15,3 \% *$ & $28,6 \% *$ & $56,1 \% *$ \\
\hline & Alto & $2,0 \% *$ & $12,0 \% *$ & $86,0 \% *$ \\
\hline \multirow{3}{*}{ Conocimientos } & Bajo & $18,5 \% *$ & $32,3 \% *$ & $49,2 \% *$ \\
\hline & Medio & $16,9 \% *$ & $16,9 \% *$ & $66,3 \% *$ \\
\hline & Alto & $2,0 \% *$ & $15,7 \% *$ & $82,4 \% *$ \\
\hline
\end{tabular}

Nota: *Diferencias significativas a un 95\% de nivel de confianza.

Fuente: Elaboración propia.

\subsection{Apoyo que los sostenedores entregan a sus establecimientos en tareas técnico pedagógicas específicas}

En relación con los desafíos en lo técnico pedagógico del nivel intermedio, la investigación nacional e internacional muestra que el apoyo que entrega este nivel a los establecimientos tiene un alto potencial de aporte dentro de los procesos de mejora educativa. Para indagar al respecto, se consultó a los sostenedores en una pregunta abierta acerca de las tres áreas principales en las que

9 Se construyó un índice con tres niveles: bajo, medio y alto, donde el nivel alto corresponde a todos los sostenedores que declaran como muy importantes el 70\% o más de los items de las funciones técnico pedagógicas, en tanto que el nivel bajo corresponde a los sostenedores que declaran como poco importantes el 30\% o menos de los ítems de las funciones técnico pedagógicas. 
prestan apoyo técnico pedagógico a los establecimientos a su cargo $\mathrm{y}$, posteriormente, se les consultó por la frecuencia con que realizaban varias actividades en sus establecimientos.

La Figura 6 entrega las respuestas espontáneas a sus prioridades de apoyo técnico pedagógico a sus establecimientos. Se aprecia que los principales apoyos mencionados tienen que ver con el diseño, implementación y evaluación del PME (51\%), el acompañamiento y retroalimentación a la práctica de los docentes (45\%), y el apoyo técnico a la gestión directiva y al jefe UTP (44\%). Cabe recordar que el involucramiento del sostenedor en los PME en los casos que aplica y el acompañamiento a los docentes están estipulados desde hace más tiempo en la normativa (PME desde 2008 y prácticas docentes desde la evaluación docente y la definición de la carrera docente). Vale decir, los sostenedores tanto públicos como privados definen sus prioridades respondiendo a las directrices de la política. Al revisar estas respuestas entre sostenedores públicos y privados solo se observan diferencias entre ellos en cuanto al apoyo a la gestión directiva y al jefe de UTP, siendo esta más frecuente en sostenedores públicos que en privados (61\% y 38\%, respectivamente).

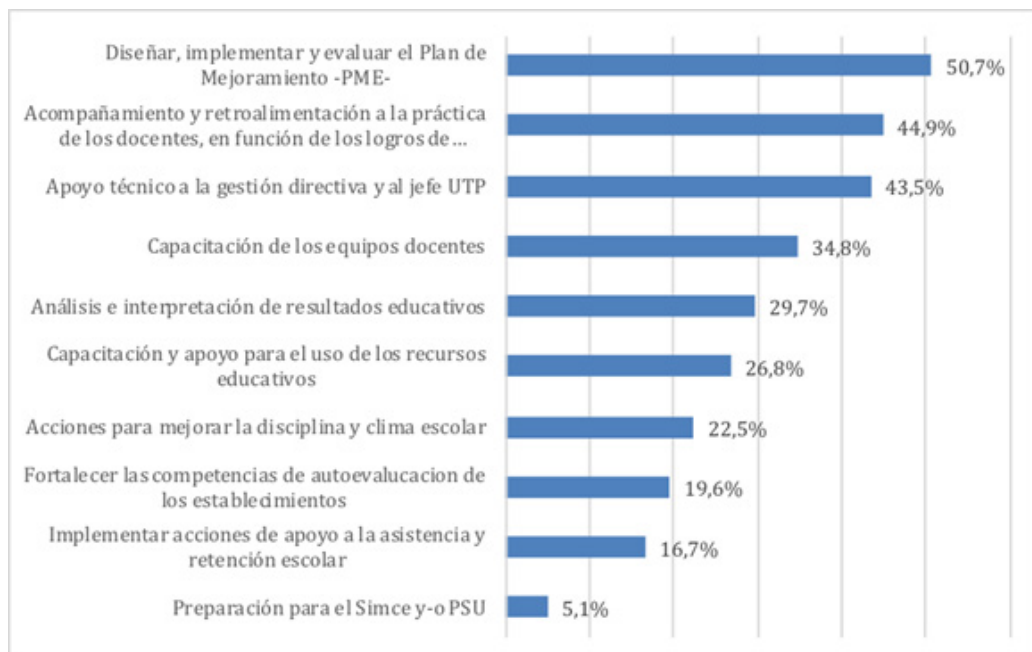

Figura 6. Las tres áreas más importantes de apoyo técnico pedagógico que presta el sostenedor (respuesta espontánea).

Fuente: Elaboración propia. 
En cuanto a la frecuencia con la que despliegan distintas acciones concretas en sus establecimientos, la Figura 7 muestra los resultados de las acciones realizadas por el propio sostenedor y su equipo en los establecimientos a su cargo. Entre las prácticas consultadas, la más frecuente -y que el 50\% de los sostenedores declara realizar semanalmente-, es la visita a establecimientos para acompañar y asesorar el trabajo directivo. Además, un tercio de ellos declara entregar semanalmente información de temas técnico pedagógicos, sugerencias a los docentes para mejorar el aprendizaje de los estudiantes, apoyar la gestión pedagógica y hacer un seguimiento curricular. Las restantes prácticas se realizan con menor frecuencia.

Llama la atención un conjunto de prácticas que un $40 \%$ o más de los sostenedores declara realizar con una frecuencia solo anual o inferior, o decididamente, no llevar a cabo. Entre estas se encuentra la revisión conjunta de las acciones y metas de la planificación institucional, generar espacios de intercambio de experiencias entre distintos establecimientos, y entregar directamente capacitaciones en torno a aspectos pedagógicos. Respecto del intercambio de experiencias entre establecimientos, alrededor de un 14\% indica no hacerlo nunca. 


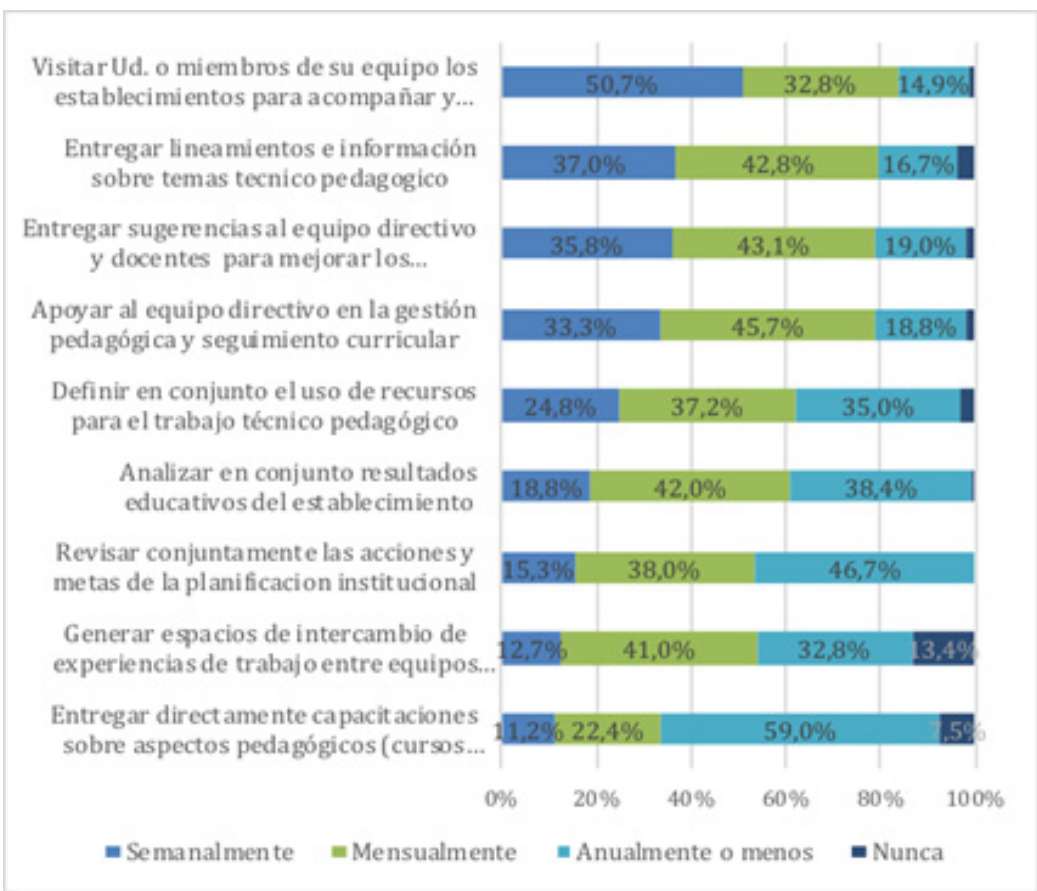

Figura 7. Frecuencia del apoyo directo que ha prestado el sostenedor en el ámbito técnico pedagógico.

Fuente: Elaboración propia.

Al desagregar esta información según las dependencias de los establecimientos, se observan diferencias estadísticamente significativas y substantivamente importantes (Tabla 5).

El apoyo directo en las cuatro áreas que muestran mayor periodicidad es significativamente más frecuente en sostenedores privados que en los públicos. De modo adicional, la generación de espacios de intercambio de establecimientos, aunque baja en los dos tipos de sostenedores, es más alta en sostenedores privados que públicos. 
408 NIVEL INTERMEDIO DEL SISTEMA ESCOLAR EN CHILE: NORMATIVA Y VISIÓN DE LOS SOSTENEDORES ACERCA DE LAS FUNCIONES, PREPARACIÓN PARA EL CARGO Y LAS PRÁCTICAS - D. Raczynski, R. Rivero y T. Yáñez

Tabla 5

Diferencias de apoyo interno semanal a establecimientos según dependencia privada o pública

\begin{tabular}{llc}
\hline & Público & Privado \\
\hline $\begin{array}{l}\text { Visitar, usted o miembros de su equipo, los establecimientos } \\
\text { para acompañar y asesorar el trabajo directivo. }\end{array}$ & $29,0 \% *$ & $57,3 \%^{*}$ \\
\hline $\begin{array}{l}\text { Entregar lineamientos e información acerca de temas técnico } \\
\text { pedagógicos. }\end{array}$ & $9,7 \% *$ & $44,9 \%^{*}$ \\
\hline $\begin{array}{l}\text { Entregar sugerencias al equipo directivo y docente para } \\
\text { mejorar los aprendizajes de los estudiantes. }\end{array}$ & $16,1 \% *$ & $41,5 \% *$ \\
\hline $\begin{array}{l}\text { Apoyar al equipo directivo en la gestión pedagógica y } \\
\text { seguimiento curricular. }\end{array}$ & $12,9 \%^{*}$ & $39,3 \%^{*}$ \\
\hline $\begin{array}{l}\text { Definir, en conjunto, el uso de recursos para el trabajo } \\
\text { técnico pedagógico. }\end{array}$ & $6,7 \%$ & $29,9 \%$ \\
\hline $\begin{array}{l}\text { Analizar, en conjunto, los resultados educativos del } \\
\text { establecimiento. }\end{array}$ & $6,5 \%$ & $22,4 \%$ \\
\hline $\begin{array}{l}\text { Revisar, conjuntamente, las acciones y metas de la } \\
\text { planificación institucional. }\end{array}$ & $3,2 \%$ & $18,9 \%$ \\
\hline $\begin{array}{l}\text { Entregar directamente capacitaciones acerca de aspectos } \\
\text { pedagógicos (cursos para docentes y directivos). }\end{array}$ & $0,0 \%$ & $14,6 \%$ \\
\hline $\begin{array}{l}\text { Generar espacios de intercambio de experiencias de trabajo } \\
\text { entre equipos directivos de distintos establecimientos. }\end{array}$ & $6,5 \% *$ & $14,6 \% *$ \\
\hline
\end{tabular}

Nota: *Diferencias significativas a un 95\% de nivel de confianza.

Fuente: Elaboración propia.

También se consultó a los sostenedores por el apoyo en temas de evaluación. Como cabe esperar, estos se aplican con una temporalidad menor, esto es, rara vez a la semana y pocas veces mensualmente (Figura 8). Entre las tres acciones que se les consultó en torno a este tema, la más frecuente es un sistema de evaluación de aprendizaje de los estudiantes, seguido por un sistema de evaluación del equipo directivo y, por último, uno propio de evaluación docente. Al desagregar estas respuestas según si el sostenedor es público o privado se detecta, nuevamente, una mayor frecuencia en los privados por sobre los públicos (un 25\% de sostenedores privados y ningún sostenedor público que lo realice semanalmente). 


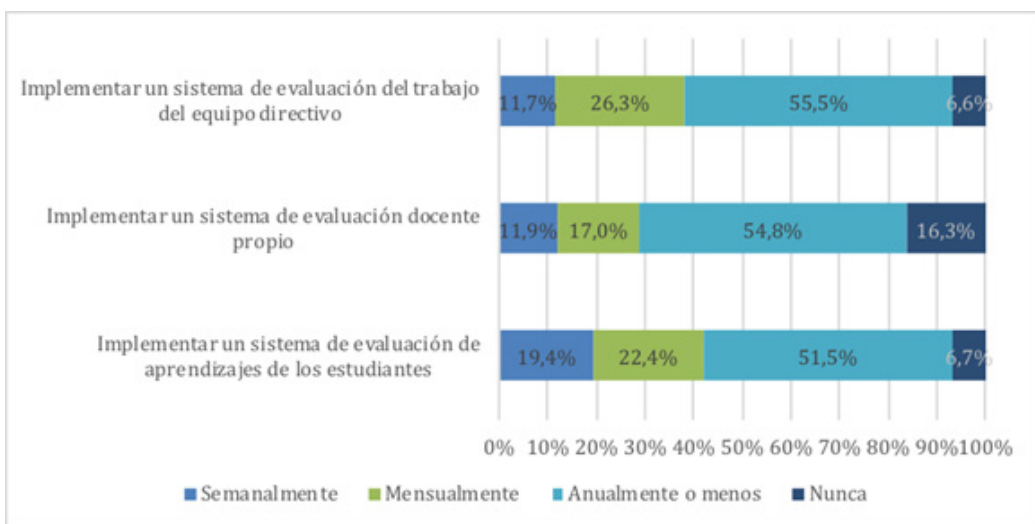

Figura 8. Frecuencia del apoyo en la evaluación que ha prestado el sostenedor. Fuente: Elaboración propia.

Finalmente, se indagó en la frecuencia de apoyo indirecto del sostenedor, mediado por la contratación de un soporte externo. Como muestra la Figura 9, esta modalidad de apoyo tiene una periodicidad menor que el apoyo directo: alrededor de un $40 \%$ de los sostenedores señala contar con este apoyo mensualmente o con mayor frecuencia. Otra vez, se aprecia que los sostenedores privados lo hacen con mayor frecuencia que los públicos (capacitación y formación: $15 \%$ de los privados y 3\% de los públicos; y asesoría externa: $17 \%$ de los privados y $6 \%$ de los públicos).

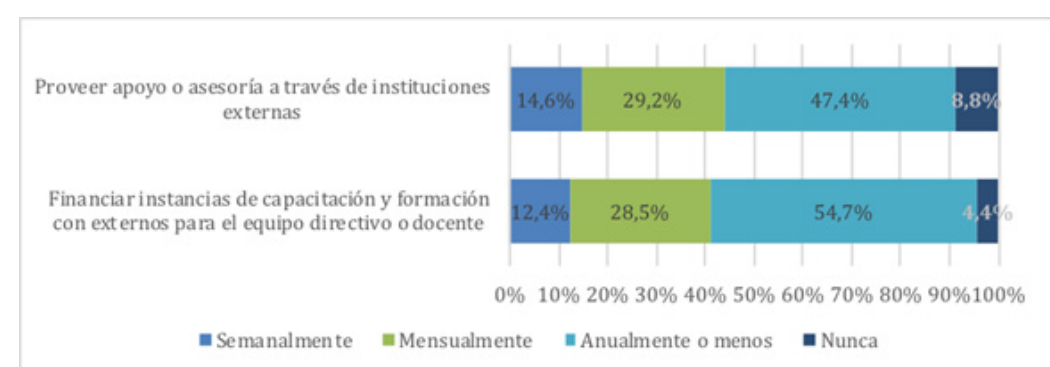

Figura 9. Frecuencia del apoyo externo que ha prestado el sostenedor en el ámbito técnico pedagógico.

Fuente: Elaboración propia.

Sintetizando la evidencia empírica acerca de la visión de los sostenedores de sus funciones prioritarias, tiempo de dedicación a ellas, preparación para el cargo y frecuencia de apoyo técnico 
410 NIVEL INTERMEDIO DEL SISTEMA ESCOLAR EN CHILE: NORMATIVA Y VISIÓN DE LOS SOSTENEDORES ACERCA DE LAS FUNCIONES, PREPARACIÓN PARA EL CARGO Y LAS PRÁCTICAS - D. Raczynski, R. Rivero y T. Yáñez

pedagógico a sus establecimientos. Las principales conclusiones son tres:

- Las funciones administrativas continúan siendo de primera prioridad para los sostenedores, tanto públicos como privados, y a ellas dedican más tiempo que a las funciones de liderazgo, desarrollo organizacional y apoyo técnico pedagógico. No obstante, las funciones no administrativas son también importantes para un porcentaje mayoritario de los sostenedores y, además, parecen haber incrementado su gravitación respecto de los diagnósticos previos a la dictación de las leyes que, gradualmente, fueron moldeando esta función. Estas leyes afectaron de forma directa más a los sostenedores públicos y son estos quienes dicen priorizar tareas asociadas a esta dimensión en mayor medida que los privados.

- Los sostenedores, públicos y privados, sienten que no es suficiente su preparación para asumir las funciones de liderazgo, de desarrollo organizacional y las técnico pedagógicas y hay un amplio espacio de mejora en ambos casos. Los sostenedores públicos declaran menor preparación que los privados en cuanto a los conocimientos referidos a la enseñanza efectiva y al desarrollo docente (gestión del currículo, procesos de aprendizaje, evaluación y desarrollo profesional).

- Considerando la frecuencia con la que declaran realizar un conjunto de actividades técnico pedagógicas, los sostenedores privados muestran mayor periodicidad, tanto en las acciones ejecutadas directamente por ellos en los establecimientos, como en las que llevan a cabo mediante subcontratación con otros.

Como conclusión general, los sostenedores públicos manifiestan un discurso que apunta a una priorización de funciones no administrativas (liderazgo, desarrollo organizacional y entrega de apoyo pedagógico a los establecimientos) más intensa que los privados, mientras que estos últimos se muestran más preparados que los públicos para realizar estas tareas y las realizan con mayor periodicidad. Lo anterior sugiere que los sostenedores públicos han asimilado a nivel discursivo lo que las normativas de política educativa delinean para ellos, pero se sienten menos preparados para 
concretizar las nuevas funciones (liderazgo, desarrollo organizacional y entrega de apoyo pedagógico a los establecimientos) y, cuando lo hacen, es con una periodicidad menor que los privados.

\section{Conclusiones y reflexión final}

A los sostenedores de establecimientos escolares en el país, a quienes hasta hace poco no se les exigía más que administrar debidamente los recursos públicos que recibían y mantener la infraestructura y equipamiento - producto de leyes destinadas a otras materias-, se le han ido agregando funciones y obligaciones nuevas asociadas con apoyar y ser corresponsable de la gestión directiva en sus establecimientos en materias pedagógicas, de convivencia escolar, de inducción y desarrollo de capacidades, entre otras. Más que administrador de sus establecimientos, entonces, se les exige que ejerzan liderazgo sobre ellos, impulsando las transformaciones necesarias para que mejore la calidad de la enseñanza y, gradualmente, ir superando sus resultados en la formación y aprendizaje de los estudiantes. Desde 2014 existe una propuesta de estándares y prácticas para la labor del sostenedor (Mineduc, 2014), documento oficial que sigue vigente, pero debe ser revisado a la luz de la Ley No 21.040 de la Nueva Educación Pública que, entre otros aspectos, explicita las responsabilidades que recaen sobre los sostenedores públicos (municipales) de educación. La propuesta de Uribe et al. (2017) avanza en esa dirección, apoyada por los aprendizajes derivados de las experiencias de otros países en cuanto al rol, funciones y prácticas del nivel intermedio que son propias de una gestión efectiva e integrando también la escasa información disponible en Chile en estudios empíricos acerca de cómo los sostenedores gestionan sus establecimientos escolares.

La postura de los sostenedores de establecimientos escolares en cuanto a la prioridad que le dan a sus funciones, el tiempo que le dedican, las prácticas que implementan y la preparación que creen tener para sus nuevas obligaciones revela la existencia de importantes brechas, tanto en el sector público como el privado subvencionado. En este plano, los resultados muestran que los sostenedores priorizan y focalizan su agenda en el desarrollo de prácticas de naturaleza 
administrativa por sobre aquellas no administrativas — dentro de las cuales se encuentran las labores técnico pedagógicas-, contando lo administrativo con una mayor asignación de importancia y tiempo de dedicación en su agenda de trabajo cotidiano. Si bien los sostenedores declaran realizar prácticas en ámbitos no administrativos, específicamente en cuanto a entregar apoyo técnico pedagógico a los equipos escolares, la frecuencia de ellas en varios aspectos es insuficiente para apoyar efectivamente a directivos y docentes en los establecimientos y fortalecer las capacidades instaladas. Este hallazgo se enfrenta con las nuevas demandas y exigencias que asigna la normativa vigente al nivel intermedio en materia pedagógica y de liderazgo.

De acuerdo con la opinión de los propios sostenedores, la preparación que estos declaran en aspectos centrales del marco de actuación del nivel intermedio elaborado por Uribe et al. (2017) es baja, con una mayoría que se considera poco o medianamente preparada respecto de los conocimientos allí considerados, así como para implementar las prácticas y habilidades allí descritas. En este ámbito se evidencian variados desafíos formativos, dentro de los que se encuentra el uso de sistemas de información y datos para orientar la gestión y trabajar el mejoramiento escolar. No se cuenta con información comparativa acerca de este tema.

Así, los resultados muestran la importancia de profundizar la formación de líderes intermedios para avanzar en el mejoramiento escolar, lograr vencer las inercias del sistema e implementar adecuadamente las nuevas demandas que la normativa asigna a este actor del sistema escolar. En esta dirección están plenamente vigentes los 12 desafíos para el nivel intermedio que plantea Uribe et al. (2017) que se reproducen en la Tabla 6. 
Tabla 6

Desafíos de la educación pública durante su fase de cambio y transición

Desafío 1: Planificar estratégicamente Construir participativamente la misión y visión con foco en lo pedagógico. estratégica del SLEP en función de asegurar un servicio de educación pública de calidad, con foco en lo pedagógico, inclusiva, con identidad y sello territorial.

Desafío 2: Movilizar las capacidades Organizar comunidades colaborativas en los y recursos para la transformación procesos de mejoramiento escolar y desarrollar cultural. un sentido de identidad con la educación pública del territorio en el marco de una nueva escala de operación.

Desafío 3: Formar equipos Constituir equipos interdisciplinarios que interdisciplinarios. permitan identificar problemas comunes a nivel local, con el fin de diseñar y coordinar planes de apoyo continuo a las unidades educativas.

Desafío 4: Generar las condiciones Generar condiciones que incentiven la captación laborales adecuadas para el bienestar y retención de profesionales competentes, a la y el desarrollo profesional de los vez que contribuyan a reducir el agobio laboral docentes. y los problemas de salud física y mental.

Desafío 5: Diseñar e implementar Como parte de la política de desarrollo de un plan de desarrollo profesional capacidades locales, orientar trayectorias docente en el territorio. laborales docentes y directivas a través de planes territoriales de formación continua y apoyar las iniciativas de perfeccionamiento de las unidades educativas.

Desafío 6: Acompañar los procesos Contextualizar de acuerdo con las de contextualización del currículo nacional. particularidades y características propias del territorio y de cada establecimiento que esté bajo la responsabilidad del equipo local de educación.

Desafío 7: Asesorar, acompañar Promover prácticas innovadoras en función de y monitorear de manera directa y los aprendizajes de los estudiantes, fortaleciendo sistemática los procesos pedagógicos el desarrollo de redes para el intercambio de en el territorio para la mejora buenas prácticas y el aprendizaje a partir educativa. de los errores cometidos, que potencien la mejora educativa y los ajustes curriculares contextualizados.

Desafío 8: Impulsar el aprendizaje Expandir la formación de los estudiantes en los profundo, fortaleciendo la formación establecimientos educacionales para desarrollar integral. ciudadanos integrales en marcos de diversidad e inclusión.

Desafío 9: Poner a disposición de Contar con equipos que orienten y apoyen las comunidades educativas equipos estrategias para el desarrollo pleno de niños, profesionales multidisciplinarios de niñas y jóvenes.

las áreas psicológica y social.

Desafío 10: Materializar esfuerzos Impulsar el mejoramiento escolar en orientados a la mejora pedagógica y jardines infantiles y establecimientos técnico curricular en todas las modalidades profesionales, de educación para adultos educativas. y en contextos de encierro (como las aulas hospitalarias). 
Desafío 11: Articular la gestión de Realizar una gestión orientada a cumplir los recursos financieros, materiales y las metas del proyecto educativo territorial pedagógicos del nivel local. relativas al fortalecimiento de la equidad y los aprendizajes de todos los estudiantes.

Desafío 12: Diseñar e implementar un Desarrollar un sistema de monitoreo y sistema de información y monitoreo evaluación integrado que, reconociendo las para la mejora educativa. particularidades del territorio, monitoree la implementación y efectividad de los planes de estudio en las unidades de su dependencia, los resultados educativos y otros indicadores de calidad integral, y evalúe sus efectos en la comunidad educativa.

Fuente: Uribe et al. (2017), p. 54.

En la línea de formación de los líderes del nivel intermedio el país cuenta con avances que requieren continuar y consolidarse, donde los centros de liderazgo escolar, apoyados por el Mineduc han iniciado esta tarea. Así, están los diplomados de formación de líderes intermedios a cargo de CEDLE y Líderes Educativos, que entregan una formación orientada a la práctica, sin perder de vista el sentido de lo que significa planificar estratégicamente con foco en lo pedagógico, movilizando capacidades y recursos para la transformación cultural, e impulsando metodologías de trabajo participativas, con control y espacios de autonomía para los establecimientos y el fomento al trabajo colaborativo entre establecimientos. A lo anterior se suma el apoyo directo que están entregando a los primeros SLEP. Por otra parte, cuando el cambio es cultural es necesario convencer a la comunidad de que este es posible, de ahí que resulta central la experiencia directa lograda por otros. En este plano es fundamental la conformación de redes de trabajo colaborativo entre directivos del nivel intermedio, iniciativa que se ha partido con una red para directores entre los primeros SLEP (Uribe et al., 2019). En cuanto a los instrumentos concretos de trabajo que puedan profesionalizar los equipos directivos del nivel intermedio -instrumentos de planificación, de monitoreo, de evaluación- la experiencia de algunos sostenedores privados a cargo de redes de establecimientos escolares representa un insumo relevante. Es así que para lograr el cambio deseado (efectividad en la labor del nivel intermedio) es importante reconocer y explicitar los siguientes puntos: 
- tan importante como los aportes y competencias técnicas y tecnológicas son las habilidades de entusiasmar, convencer, negociar y dirigir escuchando, apuntando hacia una construcción conjunta de lo que se desea lograr con los establecimientos a cargo y en el territorio en el que estos se localizan;

- consolidar cambios en la dirección señalada es un tema en parte técnico, pero por sobre todo político, como lo ilustran con su experiencia en la provincia de Ontario, Canadá, los autores Levin, Gaskell y Pollok (2007);

- no hay moldes predefinidos acerca del proceso a seguir, pero conocer las experiencias de los otros abre los ojos, entrega ideas y delinea caminos posibles; por lo que cada sostenedor deberá definir su proyecto y camino, los posibles "pequeños grandes pasos" a seguir para iniciar procesos de mejoramiento que tengan expresión en una cada vez mejor formación y aprendizaje de los estudiantes.

Por último, no está demás mencionar que hay otros factores que gravitan negativamente en el liderazgo del nivel intermedio no cubiertos en este artículo, donde destacan la falta de alineamiento en las directrices políticas hacia el nivel intermedio y los establecimientos, emanadas del Mineduc, ACE y SIE y las limitaciones en cuanto al monto y rigideces en el uso de los recursos.

\section{Referencias}

Ahumada, L., Castro, S., y Maureira, O. (2018). Modelo para el fortalecimiento del liderazgo distribuido en escuelas y liceos mediante indagación colaborativa. Nota Técnica $N^{\circ}$ 9. Recuperado de https://www. lidereseducativos.cl/wp-content/uploads/2018/12/NT9.pdf

Alarcón, J. (2016). De la administración educativa municipal a los servicios locales de educación. Buenas prácticas para a nueva institucionalidad pública de la educación chilena. Recuperado de http://cedle.cl/publicaciones/ de-la-administracion-educativa-municipal-a-los-servicios-locales-deeducacion-buenas-practicas-para-la-nueva-institucionalidad-publicade-la-educacion-chilena/

Anderson, S. (2017). El nivel intermedio en educación y el mejoramiento escolar. Informe Técnico $N^{\circ} 1$. Recuperado de https://www.lidereseducativos. cl/wp-content/uploads/2017/08/IT-01-2017.pdf 
416 NIVEL INTERMEDIO DEL SISTEMA ESCOLAR EN CHILE: NORMATIVA Y VISIÓN DE LOS SOSTENEDORES ACERCA DE LAS FUNCIONES, PREPARACIÓN PARA EL CARGO Y LAS PRÁCTICAS - D. Raczynski, R. Rivero y T. Yáñez

Aziz, C., Hevia, H., y Rivero E. (2018). Formación innovadora para lideres intermedios: Conectando el territorio para la mejora educativa. Informe Técnico $N^{o}$ 2. Recuperado de https://www.lidereseducativos.cl/ wp-content/uploads/2018/09/IT2_L6_C.A.-H.H.-E.R._Formacioninnovadora-para-lideres-intermedios_10-09.pdf

Berkowitz, D., Warner, R., \& Zoro, B. (2018). Liderar un territorio educativo: algunas nociones y herramientas para comprender y movilizar el territorio como un recurso educativo desde el nivel intermedio (Nota Técnica $\mathrm{N}^{\circ}$ 5). Recuperado de https://www.lidereseducativos.cl/wp-content/ uploads/2018/10/NT5_L3_DB-RW-BZ_Liderar-un-territorioeducativo_19-10-18.pdf

Campbell, C. \& Fullan, M. (2006). Unlocking the potential for district-wide reform. Ontario: Ministry of Education.

Carrasco, A., Bonilla, A., \& Rasse, A. (2019). Capital profesional del sector particular subvencionado en Chile: ¿Una oferta diversa o desigual? En A. Carrasco y L. M. Flores (Eds.), De la Reforma a la transformación. Capacidades, innovación y regulación de la educación chilena (pp. 449502). Santiago de Chile: Centro de Estudios de Políticas y Prácticas en Educación, CEPPE-UC.

Corvalán, J., Elacqua, G., y Salazar, F. (2009). El sector particular subvencionado en Chile. Tipologización y perspectivas frente a las nuevas regulaciones. Santiago de Chile: Departamento de Estudios y Desarrollo, Fonide, Ministerio de Educación.

Daly, A. \& Finnigan, S. (Eds.) (2016). Thinking and acting systemically. Improving school districts under pressure. Washington, D.C.: American Education Research Association Books.

Espínola, V., Chaparro, M. J., Fuenzalida, A., Silva, M. E., y Zárate, G. (2008). Estructura organizacional de la administración educativa municipal para asegurar la efectividad del apoyo y seguimiento a escuelas vulnerables. Recuperado de https://centroestudios.mineduc.cl/wp-content/uploads/ sites/100/2017/07/2007-FChile-Espinola-5.pdf

González, A., González, M., y Galdames, S. (2015). El sostenedor como agente de cambio: el rol de los coordinadores técnicos en el apoyo a los establecimientos municipales chilenos. Pensamiento Educativo, 42(1), 47-64. https://doi.org/10.7764/pel.52.1.2015.5

Fullan, M. \& Quinn, J. (2016). Coherence. Toronto: Corwin.

Hargreaves, A. \& Ainscow, M. (2015). The top and bottom of leadership and change. Phi Delta Kappa, 73(3), 42-48. https://doi. org/10.1177/0031721715614828 
Honig, M. (2012). District central office leadership as teaching: How central office administrators support principals' development as instructional leaders. Educational Administration Quarterly, 48(4), 733-774. https:// doi.org/10.1177/0013161x12443258

Horn, A., Rojas, M. E., Navarro, L, Valencia, E., y Palma, R. (2017). Propuesta de bases para la instalación de un sistema de apoyo educativo a los establecimientos de los servicios locales de educación. Cuadernos para el Desarrollo del Liderazgo Directivo, 7, 1-26. Recuperado de https:// issuu.com/cedlechile/docs/cuaderno-7-bases-para-instalacio_n-

Larrañaga, O., Peirano, C., y Falck, D. (2009). Una mirada al interior del sector municipal En M. Marcel y Raczynski (Eds.), La asignatura pendiente. Claves para la revalidación de la educación pública de gestión local en Chile (pp. 77-97). Santiago de Chile: Uqbar Editores y Corporación de Estudios para Latinoamérica, Cieplan.

Leithwood, K. (2010). Characteristics of school districts that are exceptionally effective in closing the achievement gap. Leadership and Policies in Schools, 9(3), 245-291. https://doi.org/10.1080/15700761003731500

Levin, B., Gaskell, J., \& Pollok, K. (2007). What shapes inner city education policy? Canadian Journal of Educational Administration and Policy, 61, 1-22. Recuperado de https://files.eric.ed.gov/fulltext/EJ806976.pdf

Ley No 19.979 Modifica El Regimen De Jornada Escolar Completa Diurna Y Otros Cuerpos Legales. Diario Oficial de la República de Chile, Santiago, Chile, 6 de noviembre de 2004. Recuperado de https://www.leychile. $\mathrm{cl} /$ Navegar?idNorma $=232146$

Ley No 20.248 Establece Ley De Subvención Escolar Preferencial. Diario Oficial de la República de Chile, Santiago, Chile, 1 de enero de 2008. Recuperado de https://www.leychile.cl/N?i=269001\&f=2016-03$03 \& \mathrm{p}=$

Ley No 20.370 Establece La Ley General De Educación. Diario Oficial de la República de Chile, Santiago, Chile, 12 de septiembre de 2009. Recuperado de https://www.leychile.cl/N?i=1006043\&f=2009-09$12 \& \mathrm{p}=$

Ley No 20.501 Calidad Y Equidad De La Educación. Diario Oficial de la República de Chile, Santiago, Chile, 26 de febrero de 2011. Recuperado de https://www.leychile.cl/N?i=1022346\&f=2011-09-30\&p=

Ley No 20.529 Sistema Nacional De Aseguramiento De La Calidad De La Educación Parvularia, Básica Y Media Y Su Fiscalización. Diario Oficial de la República de Chile, Santiago, Chile, 27 de agosto de 2011. Recuperado de https://www.leychile.cl/N?i=1028635\&f=2019-04$25 \& \mathrm{p}=$ 
418 NIVEL INTERMEDIO DEL SISTEMA ESCOLAR EN CHILE: NORMATIVA Y VISIÓN DE LOS SOSTENEDORES ACERCA DE LAS FUNCIONES, PREPARACIÓN PARA EL CARGO Y LAS PRÁCTICAS - D. Raczynski, R. Rivero y T. Yáñez

Ley No 20.845 De Inclusión Escolar Que Regula La Admisión De Los Y Las Estudiantes, Elimina El Financiamiento Compartido Y Prohíbe El Lucro En Establecimientos Educacionales Que Reciben Aportes Del Estado. Diario Oficial de la República de Chile, Santiago, Chile, 8 de junio de 2015. Recuperado de https://www.Leychile.Cl/ $\mathrm{N} ? \mathrm{I}=1078172 \& \mathrm{~F}=2019-04-25 \& \mathrm{P}=$

Ley N 20.903 Crea El Sistema De Desarrollo Profesional Docente Y Modifica Otras Normas. Diario Oficial de la República de Chile, Santiago, Chile, 1 de abril de 2016. Recuperado de https://www.leychile.cl/ $\mathrm{N} ? \mathrm{i}=1087343 \& \mathrm{f}=2016-04-01 \& \mathrm{p}=$

Ley No 21.040 Crea El Sistema De Educación Pública. Diario Oficial de la República de Chile, Santiago, Chile, 24 de noviembre de 2017. Recuperado de https://www.Leychile.Cl/N?I=1111237\&F=2019-04$25 \& \mathrm{P}=$

Marcel, M. y Raczynski, D. (Eds.) (2009). La asignatura pendiente. Claves para la revalidación de la educación pública de gestión local en Chile. Santiago de Chile: Uqbar Ediciones y Corporación de Estudios para Latinoamérica, Cieplan.

Ministerio de Educación de Chile, Mineduc. (2005). Marco de la buena dirección. Criterios para el desarrollo profesional y evaluación de desempeño. Recuperado de http://archivos.agenciaeducacion.cl/Marco_ para_la_Buena_Direccion.pdf

Ministerio de Educación de Chile, Mineduc. (2014). Estándares indicativos de desempeño para establecimientos y sus sostenedores. Recuperado de http://archivos.agenciaeducacion.cl/documentos-web/Estandares_ Indicativos_de_Desempeno.pdf

Ministerio de Educación de Chile, Mineduc. (2015). Marco para la buena dirección y liderazgo directivo. Recuperado de https://www.cpeip.cl/ marco-para-la-buena-direccion-y-el-liderazgo-escolar/

Ministerio de Educación de Chile, Mineduc. (2018). Estadísticas de la Educación 2017. Santiago de Chile: Autor. Recuperado de https:// centroestudios.mineduc.cl/wp-content/uploads/sites/100/2018/12/ ANUARIO-MINEDUC_VERSION-BAJA.pdf

Muñoz, G., Valdebenito, M. J., y Amenábar, J. (2018). ¿Cuánto y cómo cambian las prácticas de los directivos luego de su paso por programas de formación en liderazgo? Recuperado de https://www.lidereseducativos.cl/wpcontent/uploads/2019/01/01.-PPT-pra\%CC\%81cticas-directivas.pdf

Raczynski, D. (2012). Realidad de la educación municipal en Chile: ¿liderazgo del sostenedor municipal? En J. Weinstein y G. Muñoz (Eds.), ¿Qué sabemos sobre los directores de escuela en Chile? (pp. 181-217). 
Santiago de Chile: Fundación Chile y Pontificia Universidad Católica de Chile.

Raczynski, D. y Muñoz, G. (2005). Supervisión educacional en Chile. Experiencias públicas y privadas. Santiago de Chile: Ministerio de Educación.

Raczynski, D. y Salinas, D. (2009). Prioridades, actores y procesos en la gestión municipal de la educación. En M. Marcel y D. Raczynski (Eds.), La asignatura pendiente. Claves para la revalidación de la educación pública de gestión local en Chile (pp.135-176). Santiago de Chile: Uqbar Editores y Corporación de Estudios para Latinoamérica, Cieplan.

Rivero, E., Zoro, B., y Aziz, C. (2018). Construyendo una visión compartida para la educación del territorio (Nota Técnica $\mathrm{N}^{\circ}$ 6). Recuperado de https://www.lidereseducativos.cl/wp-content/uploads/2019/02/ NT6_Construyendo-una-visio\%CC\%81n-compartida-para-laeducacio\%CC\%81n-del-territorio_19-11-18-1-1.pdf

Rivero, R., Yáñez, T., Morandé, M. A., Raczynski, D., y Tham, M. (2018). Estudio de opinión a líderes escolares sobre las políticas de liderazgo escolar y educacional para la retroalimentación al diseño, implementación u creación de políticas 2018. Recuperado de https://www.lidereseducativos.cl/wpcontent/uploads/2019/01/15.-Presentacion-Encuesta-Directivos.pdf

Román, M. (2006). Un sistema educativo con dos cabezas: ¿quién responde por las escuelas públicas en Chile. Buenos Aires: AIQUE Educación.

Román, M., Raczynski, D., García Huidobro, J. E., Guerrero, A., Maureira, F., y Corvalán, J. (2016). Estudio levantamiento de estrategias de gestión territorial en red de establecimientos subvencionados. Recuperado de http://biblioteca.digital.gob.cl/bitstream/handle/123456789/308/ GESTION\%20EN\%20RED\%20DE\%20ESTABLECIMIENTOS. pdf?sequence $=1$ \&risAllowed $=y$

Salinas, D. \& Raczynski, D. (2009). ¿Cómo se hace realmente gestión educativa municipal. En M. Marcel y D. Raczynski (Eds.), La asignatura pendiente. Claves para la revalidación de la educación pública de gestión local en Chile (pp. 177-207). Santiago de Chile: Uqbar Editores y Corporación de Estudios para Latinoamérica, Cieplan.

The Wallace Foundation (2006). Leadership for learning: Making the connections among state, district and school policies and practices. Recuperado de https://pdfs.semanticscholar.org/0c0e/59bc0cc67d2779f8faal00979 bb83311d3d5.pdf

The Wallace Foundation (2013). Rethinking leadership: The changing role of principal supervisors. How can school districts ensure that principal supervisors are able to help principals meet the demands of their jobs? 
Recuperado de https://www.wallacefoundation.org/knowledgecenter/pages/rethinking-leadership-the-changing-role-of-principalsupervisors.aspx

Togneri, W. \& Anderson, S. (2003). Beyond islands of excellence: What districts can do to improve instruction and achievement in all schools. A Project of the Learning First Alliance [and] A Leadership Brief. Recuperado de https://files.eric.ed.gov/fulltext/ED475875.pdf

Uribe, N., Berkowitz, D., Torche, P., Galdames, S., y Zoro, B. (2017). Marco para la gestión y el liderazgo educativo local: desarrollando prácticas de liderazgo intermedio en el territorio. Recuperado de https://www. lidereseducativos.cl/wp-content/uploads/2017/08/Marco-LE.pdf

Uribe, M., Valenzuela, J. P., Anderson, S., Cuglievan, G., Núñez, I. y Hernández, C. (2019). Estudio de seguimiento y sistematización de procesos críticos en la transición de la gestión de la educación pública de los municipios a los Servicios Locales de Educación (SLEP). Santiago de Chile: Centro de Liderazgo Educativo, Pontificia Universidad Católica de Valparaíso y Centro de Investigación Avanzada en Investigación, Universidad de Chile. Recuperado de http://www.ciae.uchile.cl/ download.php?file=noticias/00_1562876235.pdf

Waters, J.T. \& Marzano, J. R. (2006). School district leadership that works. The effect of superintendent leadership on student achievement. Recuperado de https://www.ctc.ca.gov/docs/default-source/educatorprep/asc/4005rr_superintendent_leadership.pdf 